\title{
Upconversion Nanoparticles for Bioimaging and Regenerative Medicine
}

\author{
María González-Béjar*, Laura Francés-Soriano and Julia Pérez-Prieto* \\ Departamento de Química Orgánica, Instituto de Ciencia Molecular (ICMol), Universidad de Valencia, Valencia, Spain
}

Nanomaterials are proving useful for regenerative medicine in combination with stem cell therapy. Nanoparticles (NPs) can be administrated and targeted to desired tissues or organs and subsequently be used in non-invasive real-time visualization and tracking of cells by means of different imaging techniques, can act as therapeutic agent nanocarriers, and can also serve as scaffolds to guide the growth of new tissue. NPs can be of different chemical nature, such as gold, iron oxide, cadmium selenide, and carbon, and have the potential to be used in regenerative medicine. However, there are still many issues to be solved, such as toxicity, stability, and resident time. Upconversion NPs have

OPEN ACCESS

Edited by:

Brian McNeill,

University of Ottawa

Heart Institute, Canada

Reviewed by:

Michael Ming-Yuan Wei, University of Texas at Arlington, USA

Sabrina Simoncelli,

Ludwig-Maximilians-Universität

Munchen, Germany

${ }^{*}$ Correspondence:

María González-Béjar

maria.gonzalez@uv.es;

Julia Pérez-Prieto

julia.perez@uv.es

Specialty section:

This article was submitted

to Biomaterials,

a section of the journal

Frontiers in Bioengineering and

Biotechnology

Received: 30 March 2016

Accepted: 23 May 2016

Published: 13 June 2016

Citation:

González-Béjar M, Francés-Soriano L and Pérez-Prieto J (2016)

Upconversion Nanoparticles for Bioimaging and Regenerative

Medicine.

Front. Bioeng. Biotechnol. 4:47. doi: 10.3389/fbioe.2016.00047 relevant properties such as (i) low toxicity, (ii) capability to absorb light in an optical region where absorption in tissues is minimal and penetration is optimal (note they can also be designed to emit in the near-infrared region), and (iii) they can be used in multiplexing and multimodal imaging. An overview on the potentiality of upconversion materials in regenerative medicine is given.

Keywords: transparency, NIR excitation, upconverted (UV-VIS-NIR) emission, non-toxic nanoparticles, multiwavelength/multimodal bioimaging, cell behavior regulation

\section{INTRODUCTION}

Regenerative medicine aims to maintain, regenerate, and replace damaged or non-functional human cells, tissues, or organs to restore normal functions (Engel et al., 2008; Harrison and Sirivisoot, 2011; Gao et al., 2015; Mitragotri et al., 2015) via stimulating the body's own repair mechanisms. In this context, nanostructures can play an important role regarding implants or scaffolds for tissue engineering and cell therapies, e.g., nanopatterning of surfaces to elicit specific biological responses from the host tissue and organs (Engel et al., 2008; Zhang and Webster, 2009; Harrison and Sirivisoot, 2011). Thus, the generation of new surfaces, structures, and materials containing nanoparticles (NPs) can provide the possibility of mimicking the natural environment of cells and promoting certain functions, such as cell mobility, cell adhesion, and cell differentiation that would be directly related to the nanotopography of the biomaterial (Engel et al., 2008).

The capability of nanomaterials to be multifunctional, as they can consist of different functional components in a single unit, is leading to significant advances over traditional imaging, sensing, and structural technologies (Harrison and Sirivisoot, 2011). Thus, NPs are used in biomedical applications for imaging (cell tracking and visualization), therapy, drug delivery aimed at target biological functions, surface modifications of implantable materials, diagnosis (Engel et al., 2008; Harrison and Sirivisoot, 2011; Gao et al., 2015), and even in the regulation of cell behavior (adhesion, growth, and differentiation), which is of relevance in regenerative medicine (Mitragotri et al., 2015).

New smart biomaterials could be implanted to monitor and direct the regenerative process at the cellular level. For example, NPs could help to monitor a disease (e.g., via emission or magnetism) and bring about tissue repair (e.g., through light-induced targeted delivery) creating better non-invasive regenerative therapies (Harrison and Sirivisoot, 2011; Gao et al., 2015). Interestingly, stem cells have 
the ability to generate all types of tissues together with an unlimited self-renewal capacity; hence, research is focused on being able to locate, recruit, and mark these cells to monitor and/or trigger the regeneration process (Harrison and Sirivisoot, 2011).

Nanoparticles are also being explored as nanocarriers for theranostic applications (Grazú et al., 2012; Muthu et al., 2014). This new field integrates NP design with simultaneous imaging and therapy, aiming to offer individualized treatments based on in vivo molecular images to allow for a comprehensive diagnosis (Rai et al., 2010). Several NPs have been used as platforms for NP-based theranostics (Choi et al., 2012; Miao et al., 2016): gold nanoparticles (GNPs) (Gao and Li, 2016), carbon nanotubes (CNTs) (Tran et al., 2009; Yun et al., 2012; Fraczek-Szczypta, 2014), magnetic NPs (MNPs) (Gao et al., 2015), silica NPs (SNPs) (Santra et al., 2005; Vivero-Escoto et al., 2012), quantum dots (QDs) (Ho and Leong, 2010), and upconversion NPs (UCNPs) (Chen et al., 2014a), among others. Remarkably, it has been estimated that at least half of the drugs used in 2020 will be based on nanotechnology (Grazú et al., 2012).

Current methods of evaluating cell treatments typically involve destructive or invasive techniques, such as tissue biopsies, whereas traditional non-invasive methods, such as magnetic resonance imaging (MRI) and positron emission tomography (PET), rely heavily on contrast agents and usually lack the specificity or resident time to be a viable option for cell tracking (Engel et al., 2008; Harrison and Sirivisoot, 2011). Photonic applications for diagnostics, therapy, and interventional guidance are increasing (Jin et al., 2011; Rwei et al., 2015). Fiber-optic based catheters can be used to perform localized imaging or laser ablation of a desired target to treat, for example, coronary artery disease (van Soest et al., 2015). Moreover, irradiation density is easy to dose and can provide spatiotemporal control (Rwei et al., 2015; van Soest et al., 2015). The limitations of biophotonic technologies for imaging usually arise from limited penetration depth of light into tissues; however, penetration depth could reach the centimeter scale for applications that rely on near-infrared (NIR) wavelengths and on optical power (diffuse optics and sensing) (Rwei et al., 2015; van Soest et al., 2015). UCNPs are transparent to visible light but can absorb two or more photons in the NIR region and emit at a higher energy level via a non-linear conversion process. Therefore, these luminescent NPs enable high-contrast optical biomedical imaging by suppressing the background of tissue autofluorescence and avoiding high absorption of the tissue.

In this mini-review, an overview of the use of NPs in regenerative medicine and what UCNPs can offer to this field is given.

\section{NANOPARTICLES IN BIOMEDICINE}

Nanoparticles used in biomedicine must be biocompatible, water-dispersible, and stable in physiological media (Mu et al., 2014). To date, most of the ongoing nanomedicine clinical trials or those already on the market are being injected and provide passive drug targeting (Li et al., 2010; Grazú et al., 2012; Markovsky et al., 2012; Rwei et al., 2015). Therefore, the stability of nanocarriers in biological media is crucial when formulating nanomedicines (Acharya and Sahoo, 2011; Wu et al., 2011). Their aggregation and rapid clearance have to be avoided
(Veiseh et al., 2010), and their pharmacokinetic profile should be studied in advance (Grazú et al., 2012). Equally important, it is extremely difficult for a nanoplatform to selectively reach its target site (Wu et al., 2011). Currently, the most universal way to improve its affinity toward a target is by attachment of ligands [RGD (Zhou et al., 2012), antigen, and folate] that selectively recognize and bind to the target site. This active targeting, which relies on specific interactions, can lead to the accumulation of the nanoplatforms preferentially in, e.g., a tumor region, an ischemic tissue, or an inflamed area as a result of their extravasation through permeable vasculature, an effect known as enhanced permeation and retention (EPR) (Maeda, 2001; Hartner et al., 2009; Albanese et al., 2012).

Multifunctional NPs have been used to design biomaterials and nanoplatforms able to entrap and deliver drugs and biomolecules (such as DNA and growth and differentiation factors, among others bioactive agents) to cells and tissues, for the effective implementation of regenerative therapies (Panyam and Labhasetwar, 2003; Solanki et al., 2008; Grazú et al., 2012). For example, GNPs conjugated with a DNA-polymer complex have been used as nanoscaffolds for delivery of DNA into hMSCs through reverse transfection (Uchimura et al., 2007). They have also been used as a reinforcing- or bioactivity-enhancement phase for polymeric matrices in 3D scaffolds for tissue engineering (Reddy et al., 2006; Engel et al., 2008).

Nanocarriers designed for delivery are able to bypass biological barriers, such as cell membranes and the blood-brain barrier, and can be loaded with high drug concentrations of therapeutics to be released. Once the target site is reached, therapeutic drugs must be delivered from the nanocarrier in order to become bioavailable and aid the regeneration process (Qiu and Park, 2001). Passive processes, such as diffusion, particle erosion, particle degradation, and polymer swelling, can control the release (Mudshinge et al., 2011). The nanoplatform has to be stable enough to promote controlled release of cargo exclusively when triggering (Loomis et al., 2011; Wong and Choi, 2015). Interestingly, the delivery can be activated using in vivo signals, such as pH (Bigall et al., 2011; Sato et al., 2011), ion concentration, redox potential (Kang et al., 2010; Luo et al., 2011), presence of certain enzymes (de la Rica et al., 2012), and temperature (Kim and Lee, 2004). Exogenous triggering using nanomaterials responsive to light (Byoung-chan and Kun, 2012), magnetic fields (Ge et al., 2012; Hawkins et al., 2012), or ultrasounds (Epstein-Barash et al., 2010) can be advantageous, since it can control the timing and degree of release (Ganta et al., 2008), thus minimizing the drug release at off-target sites (Rwei et al., 2015).

\section{BIOIMAGING TECHNIQUES}

Bioimaging gives morphological, anatomical, and physiological information of biosamples and reports on the extension of the pathology and organ dysfunction, thus giving valuable information about selecting the best administration route of the elected drug (Naumova et al., 2014; Dong et al., 2015). Different non-invasive imaging techniques, differing in terms of sensitivity, resolution, data acquisition time, penetration 
depth, and costs, have been explored using NPs (Table 1) (Liu, 2011; Roco et al., 2011; Gao et al., 2013; Naumova et al., 2014; Prodi et al., 2015).

\section{Luminescence Imaging}

Light of an external source (UV-VIS-IR light) is absorbed by the contrast (emissive) agent (injected into the cell, tissue, or animal) and subsequently emitted at shorter or longer wavelengths. This low-cost method presents high sensitivity and enables fast analysis. Limitations of luminescence imaging (LI) are high light scattering and autofluorescence of the biological sample when using short wavelengths (UV and VIS light) (Sharma et al., 2006; Prodi et al., 2015; Wolfbeis, 2015).

TABLE 1 | Comparison of properties between different imaging techniques.

\begin{tabular}{|c|c|c|c|}
\hline Technique & Advantages & Disadvantages & $\begin{array}{l}\text { Example } \\
\text { of UCNP } \\
\text { application }\end{array}$ \\
\hline LI & $\begin{array}{l}\text { - High sensitivity } \\
\text { - High spatial resolution } \\
\text { - Short acquisition times } \\
\text { - No ionizing radiation } \\
\text { - Real-time images } \\
\text { - Low cost } \\
\text { - Multiplexing }\end{array}$ & $\begin{array}{l}\text { - High scattering } \\
\text { - } \text { Autofluorescence } \\
\text { (NIR light } \\
\text { avoids these } \\
\text { drawbacks) } \\
\text { - Limited } \\
\text { penetration } \\
\text { depth (cm) }\end{array}$ & $\begin{array}{l}\text { In vivo } \\
\text { visualization of } \\
\text { MCF-7 tumors } \\
\text { (Zhu et al., 2014) }\end{array}$ \\
\hline $\mathrm{RI}$ & $\begin{array}{l}\text { - High specificity } \\
\text { - High spatial resolution } \\
\text { - No photobleaching } \\
\text { - No autofluorescence } \\
\text { - No scattering } \\
\text { - No ionizing radiation }\end{array}$ & $\begin{array}{l}\text { - Limited } \\
\text { penetration } \\
\text { depth }(\mathrm{cm}) \\
\text { - Low sensitivity } \\
\text { - Long acquisition } \\
\text { times }\end{array}$ & $\begin{array}{l}\text { UCF-SERS } \\
\text { dual mode tag } \\
\text { for living cell } \\
\text { and in vivo } \\
\text { bioimaging (Niu } \\
\text { et al., 2014) }\end{array}$ \\
\hline CT & $\begin{array}{l}\text { - High spatial resolution } \\
\text { - Short acquisition times } \\
\text { - Unlimited penetration } \\
\text { - } \text { depth } \\
\text { - Moderately expensive }\end{array}$ & $\begin{array}{l}\text { - Limited } \\
\text { soft tissue } \\
\text { discrimination } \\
\text { - Health risks } \\
\text { (X-Ray) }\end{array}$ & $\begin{array}{l}\text { In vivo imaging } \\
\text { of different } \\
\text { organs in a } \\
\text { rat (Liu et al., } \\
\text { 2012a) }\end{array}$ \\
\hline USI & $\begin{array}{l}\text { - High sensitivity } \\
\text { - High spatial resolution } \\
\text { - Short acquisition times } \\
\text { - No ionizing radiation } \\
\text { - Real-time images } \\
\text { - Low cost }\end{array}$ & $\begin{array}{l}\text { - } \text { Limited } \\
\text { penetration } \\
\text { depth }(\mathrm{cm}) \\
\text { - Operator } \\
\text { dependent }\end{array}$ & $\begin{array}{l}\text { LI and USI dual- } \\
\text { modality imaging } \\
\text { (Jin et al., 2015) }\end{array}$ \\
\hline PAI & $\begin{array}{l}\text { - High sensitivity } \\
\text { - High specificity } \\
\text { - No ionizing radiation } \\
\text { - Short acquisition times } \\
\text { - Low cost }\end{array}$ & $\begin{array}{l}\text { - Moderate } \\
\text { penetration } \\
\text { depth }\end{array}$ & $\begin{array}{l}\text { In vivo imaging } \\
\text { of a mouse (Maji } \\
\text { et al., 2014) }\end{array}$ \\
\hline MRI & $\begin{array}{l}\text { - High specificity } \\
\text { - High spatial resolution } \\
\text { - No ionizing radiation } \\
\text { - High soft tissue } \\
\text { contrast } \\
\text { - Unlimited penetration } \\
\text { depth }\end{array}$ & $\begin{array}{l}\text { - Limited sensitivity } \\
\text { - Long acquisition } \\
\text { times } \\
\text { - Expensive }\end{array}$ & $\begin{array}{l}\text { Angiography and } \\
\text { atherosclerotic } \\
\text { plaque imaging } \\
\text { (Xing et al., } \\
\text { 2014) }\end{array}$ \\
\hline $\mathrm{NI}$ & $\begin{array}{l}\text { - High sensitivity } \\
\text { - Unlimited penetration } \\
\text { depth } \\
\text { - Short acquisition times }\end{array}$ & $\begin{array}{l}\text { - Low spatial } \\
\text { resolution } \\
\text { - Health risks } \\
\text { ( } \gamma \text {-rays) } \\
\text { - Expensive }\end{array}$ & $\begin{array}{l}\text { Lymphatic } \\
\text { system images } \\
\text { of a mouse (Sun } \\
\text { et al., 2011) }\end{array}$ \\
\hline
\end{tabular}

\section{Raman Imaging}

This is based on the Raman effect, which is the inelastic molecular scattering of incident light (Jokerst et al., 2013). Raman imaging (RI) has high specificity because each chemical bond has a characteristic vibrational energy. The absence of photobleaching and autofluorescence background when using NIR excitation makes this technique very promising in regenerative medicine (Gao et al., 2013). However, its weakness is its low photon efficiency (less than one in a million incident photons corresponds to Raman scattering), resulting in weak signals and/or long acquisition times (Liu, 2011). To increase the signal, the Raman active molecules are placed on a metallic plasmonic surface, usually GNPs, due to their very strong surface enhancement capabilities when illuminated at the plasmon resonance band (Jokerst et al., 2013). This technique is termed surface-enhanced Raman scattering (SERS) (Jokerst et al., 2013).

\section{X-Ray Computed Tomography}

This is one of the most widely used tools in clinical diagnosis due to its availability, efficiency, and low cost. It directs X-rays to a biosample and measures the decrease in intensity along a linear path, obtaining cross sectional images (Law and Wong, 2014). Computed tomography (CT) can provide anatomic and functional information of bones, organs, and tissues and is generally used in combination with other techniques, such as MRI and PET (Law and Wong, 2014). CT requires short acquisition time, has an unlimited penetration depth, and high spatial resolution; however, its weakness is that it has a limited soft tissue discrimination, and there are concerns on the health risks associated with X-ray radiation (McMahon and Currell, 2013).

\section{Ultrasound Imaging}

These images are generated from pulsed sound waves reflected and transmitted between tissue structures, which are eventually detected as echoes (time response to travel back) (Naumova et al., 2014). This technique allows real-time images, presents high sensitivity, and is low cost. However, its disadvantage is its limited penetration depth in tissues. In spite of that, this is one of the most commonly used techniques in clinical assays (Law and Wong, 2014).

\section{Photoacoustic Imaging}

The absorbed energy from an external source (VIS-IR light) is transformed into kinetic energy of the sample through energy exchange processes, i.e., the incident light is converted into ultrasonic emission (Gao and Li, 2016). This technique hybridizes the high contrast and spectral selectivity of optical imaging with high ultrasonic resolution. It is a low cost and rapid technique, but has a moderate penetration depth (Prodi et al., 2015).

\section{Magnetic Resonance Imaging}

It is based on the principles of nuclear magnetic resonance, which uses magnets to polarize the hydrogen nuclei in water molecules, thus obtaining a spatial distribution of signals emitted from protons in the tissue (Law and Wong, 2014). MRI is a popular technique for cellular imaging in large animals and humans 
due to its high temporal and spatial contrast, high specificity, absence of ionizing radiation, and unlimited penetration depth. Unfortunately, MRI is expensive and needs a long time of analysis (Yeo et al., 2014).

\section{Nuclear Imaging}

Positron emission tomography and single photon emission computed tomography (SPECT) use radionuclides (Law and Wong, 2014). PET uses biologically active positron-emitting radiotracers (such as fluorine-18) that decay and cause the annihilation of a positron and an electron producing two $\gamma$-rays. This is one of the most sensitive methods for quantitative measurement of physiologic processes in vivo (Law and Wong, 2014). SPECT consists of the emission of positrons to emit a single $\gamma$-ray, which is measured directly by rotating gamma cameras obtaining the image (Law and Wong, 2014). These methodologies possess high sensitivity and no limitations in penetration depth. The main drawbacks are the problems caused by the radiation, long acquisition times, and the presence of artifacts easily generated due to patient movement or bad distribution of the radiotracer (Law and Wong, 2014; Naumova et al., 2014).

\section{UPCONVERSION NANOPARTICLES IN BIOIMAGING}

Upconversion nanoparticles upconvert NIR light (800, 915, and $980 \mathrm{~nm}$ ) to multi-wavelength light (narrow emission bands at UV, visible, and even NIR region) using a low-power continuous-wave diode laser. NIR excitation allows for deep tissue penetration and avoids autofluorescence of the biological samples (i.e., higher sensitivity) (Philippot and Reiss, 2012; Dong et al., 2015). Moreover, the possibility of using both NIR excitation and NIR emission (NIR-to-NIR upconversion) is particularly relevant for in vivo imaging of small animals, because it permits deep tissue penetration and less absorption and scattering of bio-tissues and organs. These properties combined with their high stability, low cytotoxicity (Gnach et al., 2015; Sun et al., 2015), good photostability, and non-photoblinking or -photobleaching make UCNPs unique optical tools for biological studies (Liu, 2011; DaCosta et al., 2014; Bünzli, 2015; Dong et al., 2015; Prodi et al., 2015). The only drawback of UCNPs in LI is their relatively low upconversion quantum yield; several strategies are being explored to enhance their emission yield (such as covering the UCNPs with an inorganic shell) (Chen et al., 2014a, 2015).

Though UCNPs have been mainly used in LI, recent studies have shown their versatility for other bioimaging techniques. PEG-capped $\mathrm{NaYbF}_{4}: \mathrm{Er}^{3+}, \mathrm{Gd}^{3+} \mathrm{NPs}$ have been effectively internalized by HeLa cells and provided higher contrast images of a rat heart than equivalent concentrations of iobitridol (a current clinical contrast agent) (Liu et al., 2012a). Moreover, UCNPs can be conveniently functionalized with iodinated compounds (silica-coated UCNPs with an iodine compound attached that absorbs X-ray radiation) to make them suitable for CT imaging (Zhang et al., 2011). These UCNPs allowed the visualization of a liver for $30 \mathrm{~min}$, thus demonstrating their long circulating time. Moreover, hybrid $\mathrm{BaYbF}_{5} \mathrm{NPs}$ perform well in the in vivo X-ray
CT angiography (Liu et al., 2012b). This binary CT agent was more efficient than iobitridol and allowed the visualization of the vasculature in an in vivo mouse model during $2 \mathrm{~h}$.

Upconversion nanoparticles have also been studied as potential photoacoustic imaging (PAI) agents (Maji et al., 2014), using $\mathrm{NaYF}_{4}: \mathrm{Yb}^{3+}, \mathrm{Er}^{3+} \mathrm{NPs}$ covered with $\alpha$-cyclodextrin. Excitation at $980 \mathrm{~nm}$ of the nanosystem dispersed in water led to luminescence quenching due to non-radiative relaxation processes and brought about an enhanced photoacoustic signal. The in vivo localization of the UCNPs in mice showed their capability for PAI (Maji et al., 2014).

In addition, UCNPs containing $\mathrm{Gd}^{3+}$ as dopant and/or as host matrix have been studied as MRI contrast agents. For example, ultra-small $\mathrm{NaGdF}_{4}$ NPs have proved more efficient in MRI angiography and atherosclerotic plaque imaging than some commercial MRI contrast agents, and they were easily excreted by kidney (Xing et al., 2014). Furthermore, a chelating molecule [diethylenetriaminepentaacetic acid (DTPA)] was used to functionalize the surface of UCNPs with the aim of capturing potentially released $\mathrm{Gd}^{3+}$ ions, thus avoiding toxic effects in vivo (Xing et al., 2014). Also, $\mathrm{Gd}^{3+}$ can be incorporated in both, the NP as dopant ion and the ligand. Recent studies demonstrated that simultaneous internal and external incorporation of $\mathrm{Gd}^{3+}$ ions increase MRI sensitivity (Du et al., 2016).

Moreover, UCNPs can be used for multimodal imaging, i.e., the combination of two or more imaging techniques to benefit from their strengths and weaknesses (Chen et al., 2014a; DaCosta et al., 2014; Li et al., 2014a; Bünzli, 2015; Cheng and Lin, 2015; Christ and Schäferling, 2015; Dong et al., 2015; Park et al., 2015; Prodi et al., 2015; Rieffel et al., 2015a; Wu et al., 2015; Zhou et al., 2015). There are examples of UCNPs in bimodal imaging combining PET/LI (Sun et al., 2011), SPECT/LI (Yang et al., 2013), PAI/LI (Maji et al., 2014), MRI/LI (Zhou et al., 2010; Cheng et al., 2013a), CT/LI (Zhang et al., 2011; Liu et al., 2013a; Zheng et al., 2014), and ultrasound imaging (USI)/LI (Jin et al., 2015).

Thus, NaGdF4: $\mathrm{Yb}^{3+}, \mathrm{Er}^{3+}$, NPs functionalized with bovine serum albumin attached to DTPA-Gd ${ }^{3+}$ have proved useful in upconversion LI and MRI (Du et al., 2016). ${ }^{18} \mathrm{~F}$ radionuclide has been directly bound to the surface of $\mathrm{NaYF}_{4} \mathrm{UCNP}$ s to generate a dual-model bioimaging technique, combining upconversion LI and PET imaging (Sun et al., 2011). Several prevalent diseases are associated with the lymphatic system, which is usually difficult to study by bioimaging due to the lack of techniques with adequate sensitivity and temporal resolution. Recently, $\mathrm{NaYF}_{4}: \mathrm{Yb}, \mathrm{Tm}$ UCNPs have been labeled with ${ }^{18} \mathrm{~F}^{-}$, and the in vivo mouse distribution of ${ }^{18} \mathrm{~F}_{-} \mathrm{NaYF}_{4}: \mathrm{Yb}, \mathrm{Tm}$ UCNPs was monitored by upconversion LI. In addition, the mouse lymphatic system was imaged with ultra-high sensitivity by PET (Sun et al., 2011). Moreover, a nanohybrid comprising $\mathrm{NaYF}_{4}: \mathrm{Yb}, \mathrm{Er}$, and $\mathrm{Fe}_{3} \mathrm{O}_{4}$ NPs has shown versatile for upconversion LI and MRI. Mouse MSCs (mMSCs) were labeled with this nanohybrid, and the resulting nanoplatform was injected in mice with two wounds at opposite sides on the abdominal skin. Then, a magnet was placed on one of the wounds for $6 \mathrm{~h}$ to target magnetically the mMSCs at one of the wounds. The mMSCs were followed in vivo by LI and MRI, thus observing that the wound treated with mMSCs presented enhanced tissue repairing (Cheng et al., 2013a). 
In addition, examples of trimodal (Xing et al., 2012; Cheng et al., 2013b; Ni et al., 2014; Wang et al., 2014a; Yi et al., 2015; Zhai et al., 2015), tetramodal (Sun et al., 2013), and even hexamodal (Rieffel et al., 2015b) imaging by using UCNPs have also been reported.

\section{UPCONVERSION NANOPARTICLES IN REGENERATIVE MEDICINE}

Near-infrared light is particularly attractive to monitor cell-surface interactions in regenerative medicine (Figure 1). NIR-controlled

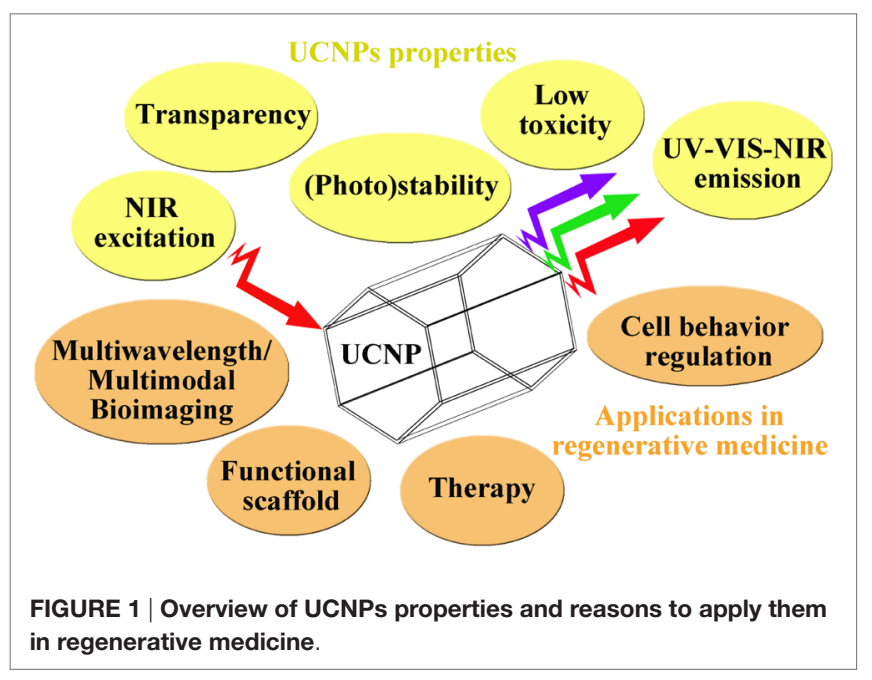

cell adhesion has been achieved with UCNP-based programmable substrates either by using photocaged linkers (Li et al., 2014b) or via photoswitchable substrates (Li et al., 2015). The UCNP harvested NIR light and converted it into UV light, thus inducing the cleavage of the photocaged linkers and on-demand release of adhesive cells ( $\mathrm{Li}$ et al., 2014b). This strategy not only enables deep tissue photocontrol of the cell adhesion on substrate but also opens a new approach to design UCNP-based cell scaffolds to manipulate dynamically cell-matrix and cell-cell interactions (Li et al., 2014b).

Cell-molecular recognition can be reversibly guided in interfacial systems by using photoswitching systems based on photoisomerization reactions (Weber et al., 2014). In this context, UCNPs have been combined with photoswitchable systems such as spiropyrans (which converts to merocyanine after ring opening) (Zhang et al., 2012a,b; Chen et al., 2014b; Lai et al., 2014; Zhou et al., 2014), as well as diarylethenes (Boyer et al., 2012; Yang et al., 2014) and azobenzenes (cis/transisomerization) (Liu et al., 2013b; Wang et al., 2014b). Recently, nanohybrids consisting of core-shell-shell-shell UCNPs, specifically, $\mathrm{NaYF}_{4}: \mathrm{Tm}, \mathrm{Yb} @ \mathrm{NaYF}_{4} @ \mathrm{NaYF}_{4}: \mathrm{Er}, \mathrm{Yb} @ \mathrm{NaYF}_{4} \mathrm{NPs}$ were coated with silica and conjugated afterward with spiropyran (Figure 2A). This system has been described as a new generation of single-wavelength NIR-controlled photoswitches, which can control the efficient adhesion and detachment of cells reversibly and non-invasively (Li et al., 2015).

Upconversion nanoparticles are unique for live cell tracking because of their optical properties (Vetrone et al., 2010; Tian et al., 2012; Li et al., 2013). Thus, silica/ $\mathrm{NaYF}_{4}: \mathrm{Yb}, \mathrm{Er}$ NPs loaded into cells were applied in cell migratory tracking
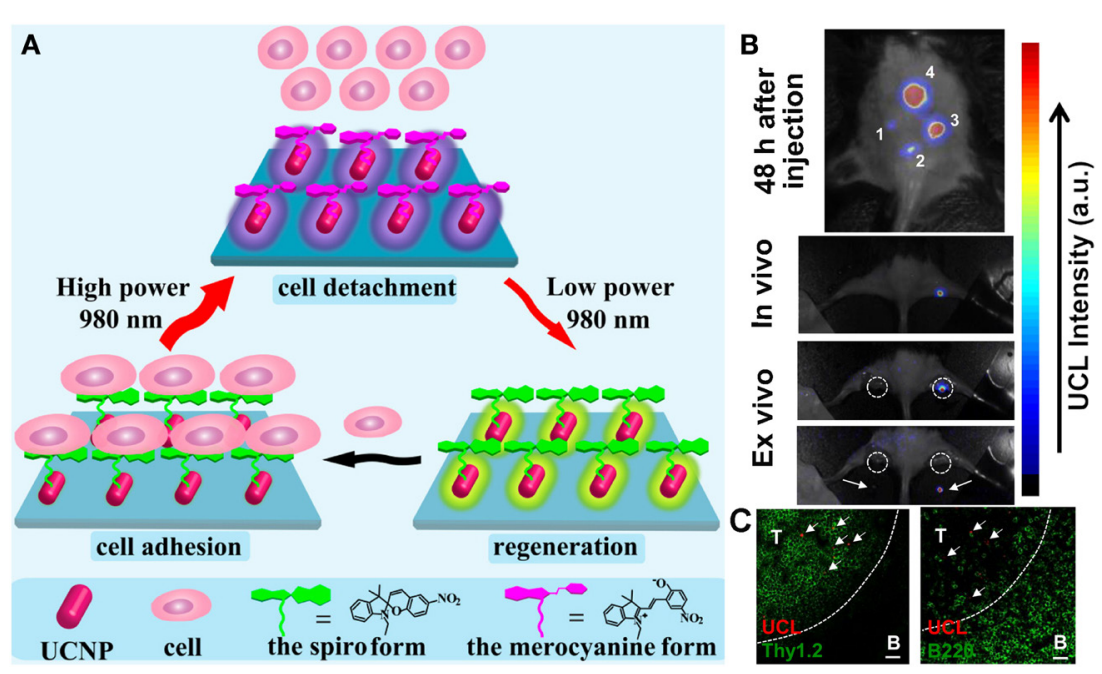

FIGURE 2 | (A) Schematic illustration of the utilization of SP-UCNP as a NIR-triggered photoswitch for non-invasive and reversible control of cell adhesion/ detachment by merely altering the power density of a single-wavelength 980-nm laser. Reprinted with permission from Li et al. (2015). Copyright (2015) American Chemical Society (Li et al., 2015). (B) Top: UCL image of a C56BL/6 mouse subcutaneously injected with various numbers of UCNPs labeled DCs ( $\approx 50-50,000)$. Middle: labeled DCs were injected into the rig; strong UCL signals from the draining lymph node were seen under in vivo UCL imaging. Bottom: ex vivo imaging of popliteal lymph nodes (white circles) before (top) and after (bottom) being dissected from the mouse. (C) Immunofluorescence images of the lymph nodes dissected from the mouse injected with UPP@OVA-labeled DCs. T: T-cell zone (Thy1.2+). B: B-cell zone (B220+). Scale bar = $20 \mu$ m. Arrows point to UCL signals from labeled DCs. Adapted with permission from Xiang et al. (2015). Copyright (2015) American Chemical Society (Xiang et al., 2015). 
for $5 \mathrm{~h}$ by a time-lapse confocal microscope. The direction, speed, and cell-cell interaction of migrating cells were clearly visualized. Consequently, the nanoplatform could be used to track live myoblast cells in a living mouse model with cryoinjured hind limb (Idris et al., 2009). Indeed polymer-coated UCNPs with different emission colors, aimed to multicolor in vivo upconversion LI, well performed in multiplexed lymph node mapping, and multicolor in vivo cancer cell tracking (Cheng et al., 2010).

Even though UCNPs have relatively low upconversion efficiencies, they have shown ultrahigh sensitivity in vivo stem cell tracking (Solanki et al., 2008; Cheng et al., 2013a; Gao et al., 2013). In addition, antigen-loaded UCNPs have recently been used to label and stimulate dendritic cells (DCs) to induce antigen-specific immune response in vivo animals (Figures 2B,C). The homing of DCs to draining lymph nodes was monitored by impressively sensitive in vivo tracking of the NP-labeled DCs by upconversion LI (Xiang et al., 2015); a few DCs were enough to be clearly seen, while, comparatively, thousands of cells are usually needed to enable in vivo tracking in mice when using QDs and MNPs (Kraitchman et al., 2005; Yukawa et al., 2010).

It is worth noting that UCNPs can be used as multifunctional nanoplatforms for light-driven therapies, such as photothermal and photodynamic therapy, and spatiocontrolled drug delivery (Chen et al., 2014a; Shanmugam et al., 2014; Rwei et al., 2015). Therefore, it is presumed that they will become relevant in cell therapy, cell therapy combined with bioimaging, and by extension in regenerative medicine.

\section{REFERENCES}

Acharya, S., and Sahoo, S. K. (2011). PLGA nanoparticles containing various anticancer agents and tumour delivery by EPR effect. Adv. Drug Deliv. Rev. 63, 170-183. doi:10.1016/j.addr.2010.10.008

Albanese, A., Tang, P. S., and Chan, W. C. W. (2012). The effect of nanoparticle size, shape, and surface chemistry on biological systems. Annu. Rev. Biomed. Eng. 14, 1-16. doi:10.1146/annurev-bioeng-071811-150124

Bigall, N. C., Curcio, A., Leal, M. P., Falqui, A., Palumberi, D., Di Corato, R., et al. (2011). Magnetic nanocarriers with tunable $\mathrm{pH}$ dependence for controlled loading and release of cationic and anionic payloads. Adv. Mater. 23, 5645-5650. doi:10.1002/adma.201103505

Boyer, J.-C., Carling, C.-J., Chua, S. Y., Wilson, D., Johnsen, B., Baillie, D., et al. (2012). Photomodulation of fluorescent upconverting nanoparticle markers in live organisms by using molecular switches. Chemistry 18, 3122-3126. doi:10.1002/chem.201103767

Bünzli, J.-C. G. (2015). Lanthanide light for biology and medical diagnosis. J. Lumin. 170, 866-878. doi:10.1016/j.jlumin.2015.07.033

Byoung-chan, B., and Kun, N. (2012). Development of polymeric cargo for delivery of photosensitizer in photodynamic therapy. Int. J. Photoenergy 2012, 1-14. doi:10.1155/2012/431975

Chen, G., Agren, H., Ohulchanskyy, T. Y., and Prasad, P. N. (2015). Light upconverting core-shell nanostructures: nanophotonic control for emerging applications. Chem. Soc. Rev. 44, 1680-1713. doi:10.1039/c4cs00170b

Chen, G., Qiu, H., Prasad, P. N., and Chen, X. (2014a). Upconversion nanoparticles: design, nanochemistry, and applications in theranostics. Chem. Rev. 114, 5161-5214. doi:10.1021/cr400425h

Chen, Z., Zhou, L., Bing, W., Zhang, Z., Li, Z., Ren, J., et al. (2014b). Light controlled reversible inversion of nanophosphor-stabilized pickering emulsions for biphasic enantioselective biocatalysis. J. Am. Chem. Soc. 136, 7498-7504. doi:10.1021/ja503123m

Cheng, L., Wang, C., Ma, X., Wang, Q., Cheng, Y., Wang, H., et al. (2013a). Multifunctional upconversion nanoparticles for dual-modal imaging-guided

\section{CONCLUSION}

Upconversion NPs have unique properties for their application in regenerative medicine. Specifically, they are considered nontoxic; can exhibit NIR-to-visible upconversion luminescence and, more importantly, NIR-to-NIR upconversion luminescence; possess extraordinary (photo)stability; and can be designed with additional features to make them useful tools for other bioimaging techniques or for multimodal imaging. Moreover, UCNPs are excellent candidates for multifunctional NP therapeutics, which can be triggered locally or remotely by NIR light. Thus, UCNPs can be relatively easily visualized in the body and can monitor the biological components and events, and/or may behave as functional scaffolds in the regeneration of damaged tissues and/or organs. Undoubtedly, UCNPs can be used for selective treatment of the affected area using photonics with simultaneous visualization of the process due to their multiwavelength emission.

\section{AUTHOR CONTRIBUTIONS}

All authors listed, have made substantial, direct and intellectual contribution to the work, and approved it for publication.

\section{FUNDING}

We thank the Spanish Ministry of Economy and Competitiveness (CTQ2014-60174-P, FPU grant to LF-S and RyC contract to MG-B).

stem cell therapy under remote magnetic control. Adv. Funct. Mater. 23, 272-280. doi:10.1002/adfm.201201733

Cheng, L., Wang, C., and Liu, Z. (2013b). Upconversion nanoparticles and their composite nanostructures for biomedical imaging and cancer therapy. Nanoscale 5, 23-37. doi:10.1039/c2nr32311g

Cheng, L., Yang, K., Zhang, S., Shao, M., Lee, S., and Liu, Z. (2010). Highly-sensitive multiplexed in vivo imaging using pegylated upconversion nanoparticles. Nano Res. 3, 722-732. doi:10.1007/s12274-010-0036-2

Cheng, Z., and Lin, J. (2015). Synthesis and application of nanohybrids based on upconverting nanoparticles and polymers. Macromol. Rapid Commun. 36, 790-827. doi:10.1002/marc.201400588

Choi, K. Y., Liu, G., Lee, S., and Chen, X. (2012). Theranostic nanoplatforms for simultaneous cancer imaging and therapy: current approaches and future perspectives. Nanoscale 4, 330-342. doi:10.1039/c1nr11277e

Christ, S., and Schäferling, M. (2015). Chemical sensing and imaging based on photon upconverting nano- and microcrystals: a review. Methods Appl. Fluoresc. 3, 034004. doi:10.1088/2050-6120/3/3/034004

DaCosta, M. V., Doughan, S., Han, Y., and Krull, U. J. (2014). Lanthanide upconversion nanoparticles and applications in bioassays and bioimaging: a review. Anal. Chim. Acta 832, 1-33. doi:10.1016/j.aca.2014.04.030

de la Rica, R., Aili, D., and Stevens, M. M. (2012). Enzyme-responsive nanoparticles for drug release and diagnostics. Adv. Drug Deliv. Rev. 64, 967-978. doi:10.1016/j.addr.2012.01.002

Dong, H., Du, S. R., Zheng, X. Y., Lyu, G. M., Sun, L. D., Li, L. D., et al. (2015). Lanthanide nanoparticles: from design toward bioimaging and therapy. Chem. Rev. 115, 10725-10815. doi:10.1021/acs.chemrev.5b00091

Du, H., Yu, J., Guo, D., Yang, W., Wang, J., and Zhang, B. (2016). Improving the MR imaging sensitivity of upconversion nanoparticles by an internal and external incorporation of the Gd3+ strategy for in vivo tumor-targeted imaging. Langmuir 32, 1155-1165. doi:10.1021/acs.langmuir.5b04186

Engel, E., Michiardi, A., Navarro, M., Lacroix, D., and Planell, J. A. (2008). Nanotechnology in regenerative medicine: the materials side. Trends Biotechnol. 26, 39-47. doi:10.1016/j.tibtech.2007.10.005 
Epstein-Barash, H., Orbey, G., Polat, B. E., Ewoldt, R. H., Feshitan, J., Langer, R., et al. (2010). A microcomposite hydrogel for repeated on-demand ultrasound-triggered drug delivery. Biomaterials 31, 5208-5217. doi:10.1016/j. biomaterials.2010.03.008

Fraczek-Szczypta, A. (2014). Carbon nanomaterials for nerve tissue stimulation and regeneration. Mater. Sci. Eng. C 34, 35-49. doi:10.1016/j.msec. 2013.09.038

Ganta, S., Devalapally, H., Shahiwala, A., and Amiji, M. (2008). A review of stimuli-responsive nanocarriers for drug and gene delivery. J. Control Release 126, 187-204. doi:10.1016/j.jconrel.2007.12.017

Gao, Y., Cui, Y., Chan, J. K. Y., and Xu, C. (2013). Stem cell tracking with optically active nanoparticles. Am. J. Nucl. Med. Mol. Imaging 3, 232-246.

Gao, Y., and Li, Y. (2016). "Gold nanostructures for cancer imaging and therapy," in Advances in Nanotheranostics I: Design and Fabrication of Theranosic Nanoparticles, ed. Z.Dai (Berlin; Heidelberg: Springer), 53-101.

Gao, Y., Lim, J., Teoh, S.-H., and Xu, C. (2015). Emerging translational research on magnetic nanoparticles for regenerative medicine. Chem. Soc. Rev. 44, 6306-6329. doi:10.1039/c4cs00322e

Ge, J., Neofytou, E., Cahill, T. J., Beygui, R. E., and Zare, R. N. (2012). Drug release from electric-field-responsive nanoparticles. ACS Nano 6, 227-233. doi:10.1021/nn203430m

Gnach, A., Lipinski, T., Bednarkiewicz, A., Rybka, J., and Capobianco, J. A. (2015). Upconverting nanoparticles: assessing the toxicity. Chem. Soc. Rev. 44, 1561-1584. doi:10.1039/c4cs00177j

Grazú, V., Moros, M., and Sánchez-Espinel, C. (2012). "Nanocarriers as nanomedicines: design concepts and recent advances," in Frontiers of Nanoscience, Vol. 4, eds J. M. de la Fuente and V. Grazú (Oxford: Elsevier), 337-440.

Harrison, B. S., and Sirivisoot, S. (2011). "Applications of nanotechnology for regenerative medicine," in Principles of Regenerative Medicine (Second edition), ed. A. A. L. A. T.Nerem (San Diego: Academic Press), 529-540.

Hartner, W. C., Verma, D. D., Levchenko, T. S., Bernstein, E. A., and Torchilin, V. P. (2009). ATP-loaded liposomes for treatment of myocardial ischemia. Wiley Interdiscip. Rev. Nanomed. Nanobiotechnol. 1, 530-539. doi:10.1002/wnan.46

Hawkins, A. M., Bottom, C. E., Liang, Z., Puleo, D. A., and Hilt, J. Z. (2012). Magnetic nanocomposite sol-gel systems for remote controlled drug release. Adv. Healthc. Mater. 1, 96-100. doi:10.1002/adhm.201100013

Ho, Y.-P., and Leong, K. W. (2010). Quantum dot-based theranostics. Nanoscale 2, 60-68. doi:10.1039/b9nr00178f

Idris, N. M., Li, Z., Ye, L., Wei Sim, E. K., Mahendran, R., Ho, P. C.-L., et al. (2009). Tracking transplanted cells in live animal using upconversion fluorescent nanoparticles. Biomaterials 30, 5104-5113. doi:10.1016/j. biomaterials.2009.05.062

Jin, B., Lin, M., You, M., Zong, Y., Wan, M., Xu, F., et al. (2015). Microbubble embedded with upconversion nanoparticles as a bimodal contrast agent for fluorescence and ultrasound imaging. Nanotechnology 26, 345601. doi:10.1088/0957-4484/26/34/345601

Jin, G., Prabhakaran, M.P., Liao, S., and Ramakrishna, S. (2011). Photosensitivematerials and potential of photocurrent mediated tissue regeneration. J. Photochem. Photobiol. B Biol. 102, 93-101. doi:10.1016/j.jphotobiol.2010.09.010

Jokerst, J. V., Pohling, C., and Gambhir, S. S. (2013). Molecular imaging with surface-enhanced Raman spectroscopy nanoparticle reporters. MRS Bull. 38. doi: $10.1557 / \mathrm{mrs} .2013 .157$

Kang, K. W., Chun, M.-K., Kim, O., Subedi, R. K., Ahn, S.-G., Yoon, J.-H., et al. (2010). Doxorubicin-loaded solid lipid nanoparticles to overcome multidrug resistance in cancer therapy. Nanomed. Nanotechnol. 6, 210-213. doi:10.1016/j. nano.2009.12.006

Kim, J.-H., and Lee, T. R. (2004). Thermo- and pH-responsive hydrogel-coated gold nanoparticles. Chem. Mater. 16, 3647-3651. doi:10.1021/cm049764u

Kraitchman, D. L., Tatsumi, M., Gilson, W. D., Ishimori, T., Kedziorek, D., Walczak, P., et al. (2005). Dynamic imaging of allogeneic mesenchymal stem cells trafficking to myocardial infarction. Circulation 112, 1451-1461. doi:10.1161/ circulationaha. 105.537480

Lai, J., Zhang, Y., Pasquale, N., and Lee, K.-B. (2014). An upconversion nanoparticle with orthogonal emissions using dual NIR excitations for controlled twoway photoswitching. Angew. Chem. Int. Ed. 53, 14419-14423. doi:10.1002/ anie. 201408219

Law, G.-L., and Wong, W.-T. (2014). "An introduction to molecular imaging," in The Chemistry of Molecular Imaging, eds N. Long and W.-T. Wong (Hoboken, NJ: John Wiley \& Sons, Inc.), 1-24.
Li, F., Feng, W., Zhou, J., and Sun, Y. (2014a). "Lanthanide-based upconversion nanophosphors for bioimaging," in The Chemistry of Molecular Imaging, eds N. Long and W.-T. Wong (Hoboken, NJ: John Wiley \& Sons, Inc.), 299-319.

Li, W., Wang, J., Ren, J., and Qu, X. (2014b). Near-infrared upconversion controls photocaged cell adhesion. J. Am. Chem. Soc. 136, 2248-2251. doi:10.1021/ ja412364m

Li, M., Al-Jamal, K. T., Kostarelos, K., and Reineke, J. (2010). Physiologically based pharmacokinetic modeling of nanoparticles. ACS Nano 4, 6303-6317. doi:10.1021/nn1018818

Li, W., Chen, Z., Zhou, L., Li, Z., Ren, J., and Qu, X. (2015). Noninvasive and reversible cell adhesion and detachment via single-wavelength near-infrared laser mediated photoisomerization. J. Am. Chem. Soc. 137, 8199-8205. doi:10.1021/ jacs. 5 b 03872

Li, W., Liu, R., Wang, Y., Zhao, Y., and Gao, X. (2013). Temporal techniques: dynamic tracking of nanomaterials in live cells. Small 9, 1585-1594. doi:10.1002/ smll.201201508

Liu, H., Lu, W., Wang, H., Rao, L., Yi, Z., Zeng, S., et al. (2013a). Simultaneous synthesis and amine-functionalization of single-phase $\mathrm{BaYF}_{5}: \mathrm{Yb} / \mathrm{Er}$ nanoprobe for dual-modal in vivo upconversion fluorescence and long-lasting X-ray computed tomography imaging. Nanoscale 5, 6023-6029. doi:10.1039/ c3nr00999h

Liu, J., Bu, W., Pan, L., and Shi, J. (2013b). NIR-triggered anticancer drug delivery by upconverting nanoparticles with integrated azobenzene-modified mesoporous silica. Angew. Chem. Int. Ed. 52, 4375-4379. doi:10.1002/ anie. 201300183

Liu, Y., Ai, K., Liu, J., Yuan, Q., He, Y., and Lu, L. (2012a). A high-performance ytterbium-based nanoparticulate contrast agent for in vivo X-Ray computed tomography imaging. Angew. Chem. Int. Ed. 51, 1437-1442. doi:10.1002/ anie.201106686

Liu, Y., Ai, K., Liu, J., Yuan, Q., He, Y., and Lu, L. (2012b). Hybrid BaYbF 5 nanoparticles: novel binary contrast agent for high-resolution in vivo $\mathrm{X}$-ray computed tomography angiography. Adv. Healthc. Mater. 1, 461-466. doi:10.1002/ adhm. 201200028

Liu, Z. (2011). "Nanoplatforms for Raman molecular imaging in biological systems," in Nanoplatform-Based Molecular Imaging, eds X. Chen (Hoboken, NJ: John Wiley \& Sons, Inc.), 197-216.

Loomis, K., McNeeley, K., and Bellamkonda, R. V. (2011). Nanoparticles with targeting, triggered release, and imaging functionality for cancer applications. Soft Matter 7, 839-856. doi:10.1039/c0sm00534g

Luo, Z., Cai, K., Hu, Y., Zhao, L., Liu, P., Duan, L., et al. (2011). Mesoporous silica nanoparticles end-capped with collagen: redox-responsive nanoreservoirs for targeted drug delivery. Angew. Chem. Int. Ed. 50, 640-643. doi:10.1002/ anie. 201005061

Maeda, H. (2001). The enhanced permeability and retention (EPR) effect in tumor vasculature: the key role of tumor-selective macromolecular drug targeting. Adv. Enzyme Regul. 41, 189-207. doi:10.1016/S0065-2571(00)00013-3

Maji, S. K., Sreejith, S., Joseph, J., Lin, M., He, T., Tong, Y., et al. (2014). Upconversion nanoparticles as a contrast agent for photoacoustic imaging in live mice. $A d v$. Mater. 26, 5633-5638. doi:10.1002/adma.201400831

Markovsky, E., Baabur-Cohen, H., Eldar-Boock, A., Omer, L., Tiram, G., Ferber, S., et al. (2012). Administration, distribution, metabolism and elimination of polymer therapeutics. J. Control Release 161, 446-460. doi:10.1016/j. jconrel.2011.12.021

McMahon, S. J., and Currell, F. J. (2013). "Gold nanoparticles for imaging and radiotherapy," in Frontiers of Nanoscience, Vol. 5, ed. S.Huw Oxford: (Elsevier), 65-93.

Miao, T., Zhang, Y., Zeng, Y., Tian, R., and Liu, G. (2016). "Functional nanoparticles for molecular imaging-guided gene delivery and therapy," in Advances in Nanotheranostics II: Cancer Theranostic Nanomedicine, ed. Z.Dai (Singapore: Springer), 273-305.

Mitragotri, S., Anderson, D. G., Chen, X., Chow, E. K., Ho, D., Kabanov, A. V., et al. (2015). Accelerating the translation of nanomaterials in biomedicine. ACS Nano 9, 6644-6654. doi:10.1021/acsnano.5b03569

Mu, Q., Jiang, G., Chen, L., Zhou, H., Fourches, D., Tropsha, A., et al. (2014). Chemical basis of interactions between engineered nanoparticles and biological systems. Chem. Rev. 114, 7740-7781. doi:10.1021/cr400295a

Mudshinge, S. R., Deore, A. B., Patil, S., and Bhalgat, C. M. (2011). Nanoparticles: emerging carriers for drug delivery. Saudi Pharm. J. 19, 129-141. doi:10.1016/j. jsps.2011.04.001 
Muthu, M. S., Leong, D. T., Mei, L., and Feng, S.-S. (2014). Nanotheranostics - application and further development of nanomedicine strategies for advanced theranostics. Theranostics 4, 660-677. doi:10.7150/thno.8698

Naumova, A. V., Modo, M., Moore, A., Murry, C. E., and Frank, J. A. (2014). Clinical imaging in regenerative medicine. Nat. Biotechnol. 32, 804-818. doi:10.1038/nbt.2993

Ni, D., Bu, W., Zhang, S., Zheng, X., Li, M., Xing, H., et al. (2014). Single $\mathrm{Ho}^{3+}-$ doped upconversion nanoparticles for high-performance $\mathrm{T}_{2}$-weighted brain tumor diagnosis and MR/UCL/CT multimodal imaging. Adv. Funct. Mater. 24, 6613-6620. doi:10.1002/adfm.201401609

Niu, X., Chen, H., Wang, Y., Wang, W., Sun, X., and Chen, L. (2014). Upconversion fluorescence-SERS dual-mode tags for cellular and in vivo imaging. ACS Appl. Mater. Interfaces 6, 5152-5160. doi:10.1021/am500411m

Panyam, J., and Labhasetwar, V. (2003). Biodegradable nanoparticles for drug and gene delivery to cells and tissue. Adv. Drug Deliv. Rev. 55, 329-347. doi:10.1016/ S0169-409X(02)00228-4

Park, Y. I., Lee, K. T., Suh, Y. D., and Hyeon, T. (2015). Upconverting nanoparticles: a versatile platform for wide-field two-photon microscopy and multi-modal in vivo imaging. Chem. Soc. Rev. 44, 1302-1317. doi:10.1039/c4cs00173g

Philippot, C., and Reiss, P. (2012). "Synthesis of inorganic nanocrystals for biological fluorescence imaging," in Frontiers of Nanoscience, eds J. M. de la Fuente and V. Grazu (Oxford: Elsevier), 4.

Prodi, L., Rampazzo, E., Rastrelli, F., Speghini, A., and Zaccheroni, N. (2015). Imaging agents based on lanthanide doped nanoparticles. Chem. Soc. Rev. 44, 4922-4952. doi:10.1039/c4cs00394b

Qiu, Y., and Park, K. (2001). Environment-sensitive hydrogels for drug delivery. Adv. Drug Deliv. Rev. 53, 321-339. doi:10.1016/S0169-409X(01)00203-4

Rai, P., Mallidi, S., Zheng, X., Rahmanzadeh, R., Mir, Y., Elrington, S., et al. (2010). Development and applications of photo-triggered theranostic agents. Adv. Drug Deliv. Rev. 62, 1094-1124. doi:10.1016/j.addr.2010.09.002

Reddy, S. T., Rehor, A., Schmoekel, H. G., Hubbell, J. A., and Swartz, M. A. (2006). In vivo targeting of dendritic cells in lymph nodes with poly(propylene sulfide) nanoparticles. J. Control Release 112, 26-34. doi:10.1016/j.jconrel.2006.01.006

Rieffel, J., Chitgupi, U., and Lovell, J. F. (2015a). Recent advances in higher-order, multimodal, biomedical imaging agents. Small 11, 4445-4461. doi:10.1002/ smll.201500735

Rieffel, J., Chen, F., Kim, J., Chen, G., Shao, W., Shao, S., et al. (2015b). Hexamodal imaging with porphyrin-phospholipid-coated upconversion nanoparticles. Adv. Mater. 27, 1785-1790. doi:10.1002/adma.201404739

Roco, M. C., Hersam, M. C., and Mirkin, C. A. (2011). Nanotechnology Research Directions for Societal Needs in 2020. Retrospective and Outlooks. Berlin; Boston: Springer, 690.

Rwei, A. Y., Wang, W., and Kohane, D. S. (2015). Photoresponsive nanoparticles for drug delivery. Nano Today 10, 451-467. doi:10.1016/j.nantod.2015.06.004

Santra, S., Dutta, D., and Moudgil, B. M. (2005). Functional dye-doped silica nanoparticles for bioimaging, diagnostics and therapeutics. Food Bioprod. Process. 83, 136-140. doi:10.1205/fbp.04400

Sato, K., Yoshida, K., Takahashi, S., and Anzai, J.-I. (2011). pH- and sugar-sensitive layer-by-layer films and microcapsules for drug delivery. Adv. Drug Deliv. Rev. 63, 809-821. doi:10.1016/j.addr.2011.03.015

Shanmugam, V., Selvakumar, S., and Yeh, C.-S. (2014). Near-infrared light-responsive nanomaterials in cancer therapeutics. Chem. Soc. Rev. 43, 6254-6287. doi:10.1039/c4cs00011k

Sharma, P., Brown, S., Walter, G., Santra, S., and Moudgil, B. (2006). Nanoparticles for bioimaging. Adv. Colloid Interface Sci. 123-126, 471-485. doi:10.1016/j. cis.2006.05.026

Solanki, A., Kim, J. D., and Lee, K.-B. (2008). Nanotechnology for regenerative medicine: nanomaterials for stem cell imaging. Nanomedicine (Lond) 3, 567-578. doi:10.2217/17435889.3.4.567

Sun, Y., Feng, W., Yang, P., Huang, C., and Li, F. (2015). The biosafety of lanthanide upconversion nanomaterials. Chem. Soc. Rev. 44, 1509-1525. doi:10.1039/ c4cs00175c

Sun, Y., Yu, M., Liang, S., Zhang, Y., Li, C., Mou, T., et al. (2011). Fluorine-18 labeled rare-earth nanoparticles for positron emission tomography (PET) imaging of sentinel lymph node. Biomaterials 32, 2999-3007. doi:10.1016/j. biomaterials.2011.01.011

Sun, Y., Zhu, X., Peng, J., and Li, F. (2013). Core-shell lanthanide upconversion nanophosphors as four-modal probes for tumor angiogenesis imaging. ACS Nano 7, 11290-11300. doi:10.1021/nn405082y
Tian, G., Gu, Z., Zhou, L., Yin, W., Liu, X., Yan, L., et al. (2012). $\mathrm{Mn}^{2+}$ dopant-controlled synthesis of $\mathrm{NaYF}_{4}: \mathrm{Yb} / \mathrm{Er}$ upconversion nanoparticles for in vivo imaging and drug delivery. Adv. Mater. 24, 1226-1231. doi:10.1002/adma.201104741

Tran, P. A., Zhang, L., and Webster, T. J. (2009). Carbon nanofibers and carbon nanotubes in regenerative medicine. Adv. Drug Deliv. Rev. 61, 1097-1114. doi:10.1016/j.addr.2009.07.010

Uchimura, E., Yamada, S., Uebersax, L., Fujita, S., Miyake, M., and Miyake, J. (2007). Method for reverse transfection using gold colloid as a nano-scaffold. J. Biosci. Bioeng. 103, 101-103. doi:10.1263/jbb.103.101

van Soest, G., Regar, E., and van der Steen, A. F. W. (2015). Photonics in cardiovascular medicine. Nat. Photon. 9, 626-629. doi:10.1038/nphoton.2015.177

Veiseh, O., Gunn, J. W., and Zhang, M. (2010). Design and fabrication of magnetic nanoparticles for targeted drug delivery and imaging. Adv. Drug Deliv. Rev. 62, 284-304. doi:10.1016/j.addr.2009.11.002

Vetrone, F., Naccache, R., Juarranz de la Fuente, A., Sanz-Rodriguez, F., BlazquezCastro, A., Rodriguez, E. M., et al. (2010). Intracellular imaging of HeLa cells by non-functionalized $\mathrm{NaYF}_{4}: \mathrm{Er}^{3+}, \mathrm{Yb}^{3+}$ upconverting nanoparticles. Nanoscale 2, 495-498. doi:10.1039/b9nr00236g

Vivero-Escoto, J. L., Huxford-Phillips, R. C., and Lin, W. (2012). Silica-based nanoprobes for biomedical imaging and theranostic applications. Chem. Soc. Rev. 41, 2673-2685. doi:10.1039/c2cs15229k

Wang, L., Liu, J., Dai, Y., Yang, Q., Zhang, Y., Yang, P., et al. (2014a). Efficient gene delivery and multimodal imaging by lanthanide-based upconversion nanoparticles. Langmuir 30, 13042-13051. doi:10.1021/la503444g

Wang, L., Dong, H., Li, Y., Xue, C., Sun, L.-D., Yan, C.-H., et al. (2014b). Reversible near-infrared light directed reflection in a self-organized helical superstructure loaded with upconversion nanoparticles. J. Am. Chem. Soc. 136, 4480-4483. doi:10.1021/ja500933h

Weber, T., Chandrasekaran, V., Stamer, I., Thygesen, M. B., Terfort, A., and Lindhorst, T. K. (2014). Switching of bacterial adhesion to a glycosylated surface by reversible reorientation of the carbohydrate ligand. Angew. Chem. Int. Ed. 53, 14583-14586. doi:10.1002/anie.201409808

Wolfbeis, O. S. (2015). An overview of nanoparticles commonly used in fluorescent bioimaging. Chem. Soc. Rev. 44, 4743-4768. doi:10.1039/c4cs00392f

Wong, P. T., and Choi, S. K. (2015). Mechanisms of drug release in nanotherapeutic delivery systems. Chem. Rev. 115, 3388-3432. doi:10.1021/cr5004634

Wu, L., Zhang, J., and Watanabe, W. (2011). Physical and chemical stability of drug nanoparticles. Adv. Drug Deliv. Rev. 63, 456-469. doi:10.1016/j.addr.2011.02.001

Wu, X., Chen, G., Shen, J., Li, Z., Zhang, Y., and Han, G. (2015). Upconversion nanoparticles: a versatile solution to multiscale biological imaging. Bioconjug. Chem. 26, 166-175. doi:10.1021/bc5003967

Xiang, J., Xu, L., Gong, H., Zhu, W., Wang, C., Xu, J., et al. (2015). Antigen-loaded upconversion nanoparticles for dendritic cell stimulation, tracking, and vaccination in dendritic cell-based immunotherapy. ACS Nano 9, 6401-6411. doi:10.1021/acsnano.5b02014

Xing, H., Bu, W., Zhang, S., Zheng, X., Li, M., Chen, F., et al. (2012). Multifunctional nanoprobes for upconversion fluorescence, MR and CT trimodal imaging. Biomaterials 33, 1079-1089. doi:10.1016/j.biomaterials.2011.10.039

Xing, H., Zhang, S., Bu, W., Zheng, X., Wang, L., Xiao, Q., et al. (2014). Ultrasmall NaGdF4 nanodots for efficient MR angiography and atherosclerotic plaque imaging. Adv. Mater. 26, 3867-3872. doi:10.1002/adma.201305222

Yang, T., Liu, Q., Li, J., Pu, S., Yang, P., and Li, F. (2014). Photoswitchable upconversion nanophosphors for small animal imaging in vivo. RSC Adv. 4, 15613-15619. doi:10.1039/c3ra47529h

Yang, Y., Sun, Y., Cao, T., Peng, J., Liu, Y., Wu, Y., et al. (2013). Hydrothermal synthesis of $\mathrm{NaLuF}_{4}:{ }^{153} \mathrm{Sm}, \mathrm{Yb}, \mathrm{Tm}$ nanoparticles and their application in dual-modality upconversion luminescence and SPECT bioimaging. Biomaterials 34, 774-783. doi:10.1016/j.biomaterials.2012.10.022

Yeo, D. C., Minocha, R., and Xu, C. (2014). "Cell engineering with nanoparticles for cell imaging," in Micro- and Nanoengineering of the Cell Surface, ed. J. M. K.Zhao (Oxford: William Andrew Publishing), 241-251.

Yi, Z., Lu, W., Liu, H., and Zeng, S. (2015). High quality polyacrylic acid modified multifunction luminescent nanorods for tri-modality bioimaging, in vivo long-lasting tracking and biodistribution. Nanoscale 7, 542-550. doi:10.1039/ c4nr05161k

Yukawa, H., Kagami, Y., Watanabe, M., Oishi, K., Miyamoto, Y., Okamoto, Y., et al. (2010). Quantum dots labeling using octa-arginine peptides for imaging of adipose tissue-derived stem cells. Biomaterials 31, 4094-4103. doi:10.1016/j. biomaterials.2010.01.134 
Yun, Y., Pixley, S., Cui, X. T., Dong, Z., Collins, B., Shanov, V., et al. (2012). Carbon nanomaterials: from therapeutics to regenerative medicine. J. Nanomed. Biother. Discov. 2. doi:10.4172/2155-983x.1000104

Zhai, X., Lei, P., Zhang, P., Wang, Z., Song, S., Xu, X., et al. (2015). Growth of lanthanide-doped $\mathrm{LiGdF}_{4}$ nanoparticles induced by $\mathrm{LiLuF}_{4}$ core as tri-modal imaging bioprobes. Biomaterials 65, 115-123. doi:10.1016/j.biomaterials.2015.06.023

Zhang, B. F., Frigoli, M., Angiuli, F., Vetrone, F., and Capobianco, J. A. (2012a). Photoswitching of bis-spiropyran using near-infrared excited upconverting nanoparticles. Chem. Commun. 48, 7244-7246. doi:10.1039/c2cc33052k

Zhang, C., Xu, C.-H., Sun, L.-D., and Yan, C.-H. (2012b). Photoswitchable upconversion luminescence of rare-earth nanophosphors with covalently grafted spiropyran. Chem. Asian J. 7, 2225-2229. doi:10.1002/asia.201200446

Zhang, G., Liu, Y., Yuan, Q., Zong, C., Liu, J., and Lu, L. (2011). Dual modal in vivo imaging using upconversion luminescence and enhanced computed tomography properties. Nanoscale 3, 4365-4371. doi:10.1039/c1nr10736d

Zhang, L., and Webster, T. J. (2009). Nanotechnology and nanomaterials: promises for improved tissue regeneration. Nano Today 4, 66-80. doi:10.1016/j. nantod.2008.10.014

Zheng, X., Zhou, L., Bu, Y., Yin, W., Hu, Z., Li, M., et al. (2014). $\mathrm{Er}^{3+}$-doped $\mathrm{YbPO}_{4}$ up-conversion porous nanospheres for UCL/CT bimodal imaging in vivo and chemotherapy. J. Mater. Chem. B 2, 6508-6516. doi:10.1039/c4tb00880d

Zhou, A., Wei, Y., Wu, B., Chen, Q., and Xing, D. (2012). Pyropheophorbide A and $\mathrm{c}(\mathrm{RGDyK})$ comodified chitosan-wrapped upconversion nanoparticle for targeted near-infrared photodynamic therapy. Mol. Pharm. 9, 1580-1589. doi:10.1021/mp200590y
Zhou, J., Liu, Q., Feng, W., Sun, Y., and Li, F. (2015). Upconversion luminescent materials: advances and applications. Chem. Rev. 115, 395-465. doi:10.1021/ cr400478f

Zhou, J., Sun, Y., Du, X., Xiong, L., Hu, H., and Li, F. (2010). Dual-modality in vivo imaging using rare-earth nanocrystals with near-infrared to near-infrared (NIR-to-NIR) upconversion luminescence and magnetic resonance properties. Biomaterials 31, 3287-3295. doi:10.1016/j.biomaterials.2010.01.040

Zhou, L., Chen, Z., Dong, K., Yin, M., Ren, J., and Qu, X. (2014). DNA-mediated construction of hollow upconversion nanoparticles for protein harvesting and near-infrared light triggered release. Adv. Mater. 26, 2424-2430. doi:10.1002/ adma.201304437

Zhu, X., Da Silva, B., Zou, X., Shen, B., Sun, Y., Feng, W., et al. (2014). Intra-arterial infusion of PEGylated upconversion nanophosphors to improve the initial uptake by tumors in vivo. $R S C A d v .4,23580-23584$. doi:10.1039/c4ra01815j

Conflict of Interest Statement: The authors declare that the research was conducted in the absence of any commercial or financial relationships that could be construed as a potential conflict of interest.

Copyright (C) 2016 González-Béjar, Francés-Soriano and Pérez-Prieto. This is an open-access article distributed under the terms of the Creative Commons Attribution License (CC BY). The use, distribution or reproduction in other forums is permitted, provided the original author(s) or licensor are credited and that the original publication in this journal is cited, in accordance with accepted academic practice. No use, distribution or reproduction is permitted which does not comply with these terms. 